\title{
STUDIES ON GALLBLADDER FUNCTION
}

\author{
II. The Absorption of Sodium Tetraiodophenolphthalein \\ FROM THE GALLBLADDER \\ By CHARLES G. JOHNSTON ${ }^{1}$ \\ (From the Laboratory of Surgical Research, University of Pennsylvania, Philadel phia)
}

(Received for publication November 22, 1930)

Although many data have been presented in the past few years which indicate that the gallbladder empties its contents through the cystic duct, there are those who believe that removal of the contents of the gallbladder is brought about entirely by an absorptive mechanism (Blond (1), Sweet (2), Demel and Brummelkamp (3), and Halpert (4)). Recently several of the workers who do not accept the contractile theory $(1,2)$ of gallbladder evacuation, have maintained that the disappearance of the gallbladder shadow in cholecystography is dependent on absorption from the gallbladder rather than the passage of the dye through the cystic duct.

The hypothesis presented by these workers $(1,2)$ should not be a difficult one to prove or disprove by experimental methods. If the hypothesis is correct in whole or in part, there should be: (1) a gradual disappearance of the shadow whether the egress of bile from the cystic duct were prevented or not; and even though the cystic duct be occluded (2) a greater rapidity in the disappearance of the shadow following a fat meal; and (3) a rapid decrease in the amount of dye in the gallbladder as estimated by analytical methods. It was to test these criteria that these studies have been made.

\section{METHOD}

The experiments in this report were carried out on dogs. The technique employed was similar to that used by workers who have attempted to drain separate lobes of the liver. In the main we have

${ }^{1}$ Harriett M. Frazier Fellow in Surgery: 
followed the technique of Sweet. With this technique advantage is taken of the fact that in the dog the right lower lobe duct enters the commonduct a short distance from the entrance of the common duct into the duodenum (fig. 1). Animals fasted for 12 hours were operated upon under sodium amytal anesthesia. A ligature was placed on the common duct and left hepatic duct above the point of entrance of the right lower lobe duct. The common duct was cannulated below the

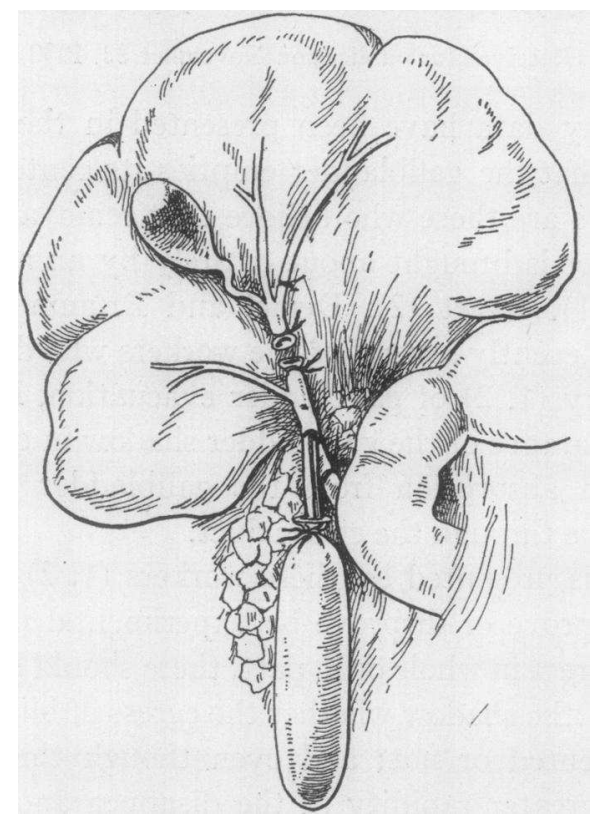

Fig. 1. Method of Cannulization Which Permis Collection of Bile from Right Lower Lobe Duct

entrance of the right lower lobe duct and the bile from this was allowed to flow into a rubber bag left inside the abdomen. Material from the gallbladder cannot find its way into the bag directly, but in order to reach the bag must pass into and be excreted by the right lower lobe of the liver after being absorbed from the gallbladder, or find its way into the liver through an open duct which connects the liver and gallbladder. Sodium tetraiodophenolphthalein or potassium iodide was introduced into the gallbladder by puncturing the gall- 
bladder wall with a small bore needle, removing the bile contained within, and introducing the salt before removing the needle. The puncture hole was tied off by a purse string suture. The animals were sacrificed at the end of 24 hours and the contents of the gallbladder and collecting bag removed, to be analyzed for iodine. Each animal was $\mathrm{x}$-rayed immediately after the operation and just before being sacrificed.

The method of Fresenius (5) for iodine assay was used for the most part, except in a few instances when iodine was determined by the method of Kendall (6) for purposes of comparison. Either of these methods is suitable, the Fresenius method being, in our experience, simpler and more dependable when determining as large quantities as were used in these experiments. With either method, the material was fused with sodium hydroxide and sodium nitrate as described by Kendall (6).

\section{RESULTS}

In the first group of animals the ducts were prepared as described and a known amount of potassium iodide was placed in the gallbladder. The animals were not fed during the succeeding 24 hours. Reference to table 1 shows that a major portion of the potassium iodide left the gallbladder during the course of the experiment and a large portion of this was recovered from the collecting bag draining the right lower lobe of the liver.

In a second group of animals known amounts of sodium tetraiodophenolphthalein were introduced into the gallbladder with a similar technique (table 2). In these experiments we found that iodine did not leave the gallbladder as rapidly as when potassium iodide was used. Twenty-four hours after the introduction of the potassium iodide 2.7 to 6.7 per cent of the original amount was recovered from the gallbladder. In the experiments with sodium tetraiodophenolphthalein from 36.9 to 55.8 per cent was recovered from the gallbladder.

These experiments with potassium iodide and sodium tetraiodophenolphthalein were performed during a period of fasting. It was deemed advisable to repeat the sodium tetraiodophenolphthalein experiments and to observe the effect of a fat meal on the disappearance of the dye from the gallbladder. 
Three animals were given $100 \mathrm{cc}$. of cream six hours before being killed. In these animals from 12.3 to 21.4 per cent of the iodine was recovered from the gallbladder. These percentages (table 3 ) approach those obtained from fasting animals with the use of potassium iodide.

Since the animals studied in Groups I, II, and III had an open cystic duct which would permit of direct communication with the

TABLE 1

Recovery of iodine from gallbladder and right hepatic duct following introduction of potassium iodide

\begin{tabular}{r|c|c|c|c|c|c}
\hline Dog & Date & $\begin{array}{c}\text { Amount of } \\
\text { salt placed in } \\
\text { gallbladder }\end{array}$ & $\begin{array}{c}\text { Amount of } \\
\text { iodine } \\
\text { glaced in } \\
\text { gallbladder }\end{array}$ & $\begin{array}{c}\text { Amount of } \\
\text { iodine recov- } \\
\text { ered from } \\
\text { gallbladder }\end{array}$ & $\begin{array}{c}\text { Amount of iodine } \\
\text { recovered from } \\
\text { bag }\end{array}$ & $\begin{array}{c}\text { Percentage } \\
\text { iodine recor- } \\
\text { ered from } \\
\text { gallbladder }\end{array}$ \\
\cline { 2 - 5 } & 1930 & grams & grams & grams & grams & \\
9 & January 21 & 0.925 & 0.707 & 0.019 & 0.098 & 2.7 \\
17 & February 14 & 0.414 & 0.316 & 0.020 & 0.087 & 6.3 \\
20 & February 22 & 0.411 & 0.314 & 0.021 & No collection & 6.7 \\
21 & February 22 & 0.400 & 0.306 & 0.010 & 0.093 & 3.3 \\
\hline
\end{tabular}

TABLE 2

Recovery of iodine from gallbladder and right hepatic duct following introduction of sodium tetraiodophenolphthalein

\begin{tabular}{c|c|c|c|c|c|c}
\hline Dog & Date & $\begin{array}{c}\text { Amount of } \\
\text { salt placed in } \\
\text { gallbladder }\end{array}$ & $\begin{array}{c}\text { Amount of } \\
\text { iodine placed } \\
\text { in gallbladder }\end{array}$ & $\begin{array}{c}\text { Amount of } \\
\text { iodine recov- } \\
\text { ered from } \\
\text { gallbladder }\end{array}$ & $\begin{array}{c}\text { Amount of } \\
\text { iodine recov- } \\
\text { ered from } \\
\text { bag }\end{array}$ & $\begin{array}{c}\text { Percentage } \\
\text { iodine recov- } \\
\text { ared from } \\
\text { gallbladder }\end{array}$ \\
\cline { 2 - 4 } 15 & February 7 & 0.500 & 0.300 & 0.156 & 0.021 & 52.0 \\
27 & March 27 & 0.542 & 0.325 & 0.120 & 0.054 & 36.9 \\
28 & March 27 & 0.418 & 0.251 & 0.140 & 0.031 & 55.8 \\
\hline
\end{tabular}

Cystic and accessory ducts not occluded.

No food given animals.

liver a fourth group of animals, whose cystic ducts were occluded, was studied. In order to ascertain whether feeding affected the rate of absorption of the iodine in this group some of the animals were given $100 \mathrm{cc}$. of cream 6 hours before being sacrificed while others were fasted during the entire experiment.

The occlusion of the cystic duct was obtained in some animals by a ligature which excluded the cystic blood vessels. In order to be 
certain that the ligature was not influencing the results by obstructing lymph vessels, the ducts, in other animals were not tied, but were occluded by filling the lumen of the common and hepatic ducts above the ligature with low melting point paraffin. The results by either

TABLE 3

Recovery of iodine from gallbladder and right hepatic duct following introduction of sodium tetraiodophenolphthalein*

\begin{tabular}{c|c|c|c|c|c|c}
\hline Dog & Date & $\begin{array}{c}\text { Amount of } \\
\text { salt placed in } \\
\text { gallbladder }\end{array}$ & $\begin{array}{c}\text { Amount of } \\
\text { iodine } \\
\text { placed in } \\
\text { gallbladder }\end{array}$ & $\begin{array}{c}\text { Amount of } \\
\text { iodine recov- } \\
\text { ered from } \\
\text { gallbladder }\end{array}$ & $\begin{array}{c}\text { Amount of iodine } \\
\text { recovered from } \\
\text { bag }\end{array}$ & $\begin{array}{c}\text { Percentage } \\
\text { iodine recov- } \\
\text { ered from } \\
\text { gallbladder }\end{array}$ \\
\cline { 2 - 4 } 16 & February 7 & 0.500 & 0.300 & 0.037 & 0.120 & 12.3 \\
37 & May 2 & 0.500 & 0.300 & 0.049 & 0.092 & 16.3 \\
38 & May 2 & 0.560 & 0.336 & 0.072 & No collection & 21.4 \\
\hline
\end{tabular}

* 100 cc. cream given on day following operation.

Cystic and accessory ducts not occluded.

TABLE 4

Recovery of iodine from gallbladder and right hepatic duct following introduction of sodium tetraiodophenolphthalein

\begin{tabular}{c|c|c|c|c|c|c}
\hline Dog & Date & $\begin{array}{c}\text { Amount of } \\
\text { salt placed in } \\
\text { gallbladder }\end{array}$ & $\begin{array}{c}\text { Amount of } \\
\text { iodine } \\
\text { placed in } \\
\text { gallbladder }\end{array}$ & $\begin{array}{c}\text { Amount of } \\
\text { iodine recov- } \\
\text { ered from } \\
\text { gallbladder }\end{array}$ & $\begin{array}{c}\text { Amount of iodine } \\
\text { recovered from } \\
\text { bag }\end{array}$ & $\begin{array}{c}\text { Percentage } \\
\text { iodine recov- } \\
\text { ered from } \\
\text { gallbladder }\end{array}$ \\
\cline { 2 - 5 } 39 & 1930 & grams & grams & grams & grams & \\
40 & May 7 & 0.497 & 0.298 & 0.152 & No collection & $51.0^{*}$ \\
41 & May 8 & 0.195 & 0.117 & 0.031 & 0.025 & $26.5^{*}$ \\
45 & May 12 & 0.507 & 0.304 & 0.111 & 0.030 & $36.5^{*}$ \\
42 & June 4 & 0.509 & 0.305 & 0.100 & 0.012 & $32.8^{*}$ \\
43 & May 19 & 0.500 & 0.300 & 0.090 & No collection & $30.0 \dagger$ \\
\hline
\end{tabular}

Cystic duct occluded.

* 100 cc. cream given on day following operation.

$\dagger$ No food given animal.

method were identical: From 26.5 to 51.0 per cent of the iodine was recovered from the gallbladder at the conclusion of the experiments (table 4). The results are similar to those obtained from fasting animals without occlusion of the cystic duct.

In the experiments in which sodium tetraiodophenolphthalein was 
placed in the gallbladder there was, at autopsy, a coating of blue material upon the walls. This proved to be concentrated salt and mucus and required careful scraping and washing to remove it. The dye remaining on the mucosa contained most of the iodine remaining in the gallbladder and if this were not taken into account the apparent disappearance of the material would be increased to a great extent.

\section{DISCUSSION}

It is of definite importance in clinical cholecystography to know whether the disappearance of the shadow is the result of absorption of the dye through the gallbladder wall, or whether it is the result of a contractile mechanism which empties the gallbladder. Sweet (2), from a study which was in certain respects similar to this one, in that he obtained his data from experiments comparable to the experiments in Group II, concluded that the changes in the gallbladder shadow in cholecystography should be interpreted as the result of absorption. This would confirm his statement that he has not found it necessary to change his conclusions expressed in 1923 that, "under normal conditions, whatever passes into the gallbladder through the cystic duct never passes out again through the cystic duct." Halpert, whose early experiments (7) with methylene blue had led him to similar conclusions, has since repeated his experiments (8) and found it necessary to alter his previous conception.

The experiments reported in table 1 show that potassium iodide is rapidly absorbed from the gallbladder. However, it is not logical to deduce that a complex salt such as sodium tetraiodophenolphthalein will do likewise. In the experiments reported in table 2 where the latter salt is used under similar conditions the iodine remains in the gallbladder in greater amounts over the same period of time.

There is, however, a serious defect in the planning of this experiment. The cystic and central hepatic ducts are patent, as are the accessory ducts emptying into the cystic duct so that a direct communication exists between the gallbladder and the liver. It was because of this that the experiments reported in tables 3 and 4 were planned. In the experiments reported in table 3 the animals were given a fat meal six hours before being sacrificed. The disappearance of a greater amount of iodine can be interpreted in one of two ways. 
It could be argued that the fat meal increased absorption. On the other hand, the proponents of the contractile theory of gallbladder evacuation might say that it forced the dye into the hepatic ducts, to the liver, and was then excreted through channels which were not occluded.

The experiments reported in table 4 were done on animals whose cystic and accessory ducts were occluded, as was proven at autopsy. Some received a fat meal while others were fasted. In these experiments the amount of iodine recovered from the gallbladder closely simulates that recovered from the fasting dog whose cystic duct was not occluded. In the light of these experiments it is impossible to draw the conclusion that a fat meal increases absorption from the gallbladder under the conditions of these experiments.

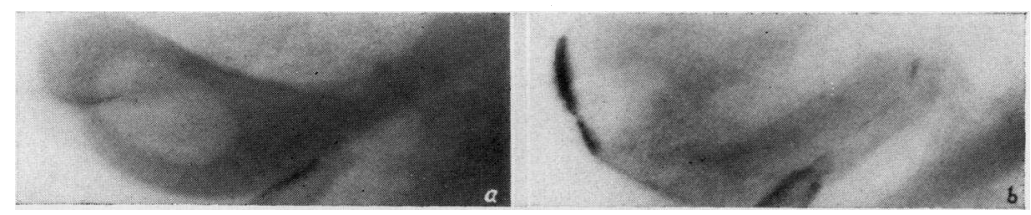

Fig. 2. Roentgenograms of Gallbladder of Dog 38 Taken; $(A)$ Immediately AFTER THE INJECTION OF SODIUM TETRAIODOPHENOLPHTHALEIN INTO the Gallbladder, aNd (B) 24 Hours after the InJection

An air bubble is seen in $A$; bile ducts are outlined in both pictures. $B$ shows a well outlined periphery.

On the other hand, roentgenograms taken in these experiments indicate that the dye does escape from a patent cystic duct when a fat meal is given (fig. 2). The use of roentgenograms for the determination of the quantity of iodine remaining in the gallbladder proved to be unreliable. This is to be expected upon theoretical grounds, as there are many variables to be considered, such as the size of the animal, the concentration of the salt within the gallbladder, and the size of the gallbladder. The last two of these factors will be affected by variation in the rate of water absorption from the gallbladder. While it is true that in all our experiments there was a decrease in the density of the gallbladder shadow, the lessened density was not always proportional to the decrease of iodine within the gallbladder. 
Sweet (2) contends that in the human subject the gallbladder shadow becomes smaller because the iodine is absorbed from around the walls of the gallbladder so that the concentration of iodine becomes lessened at the periphery and the shadow is cast by the concentrated dye remaining in the center of the gallbladder. When one considers that the gallbladder is kept in motion by respiratory movements, it is

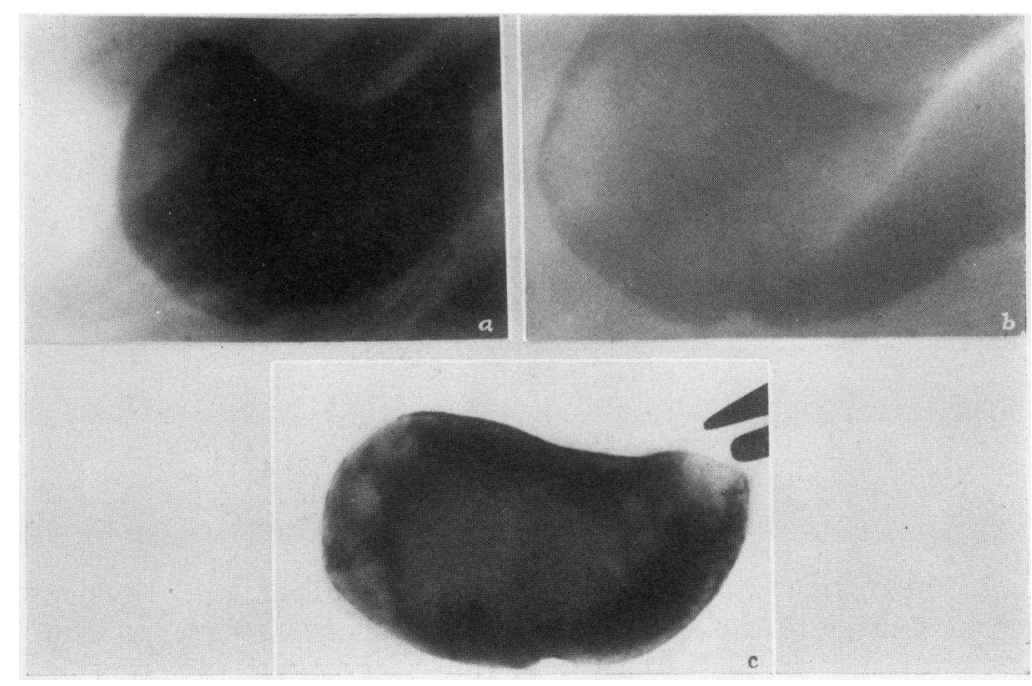

Fig. 3. Roentgenograms of Gallbladder of Dog 10, an Experiment Similar to Those in TaBle 2

$A$ was taken immediately after the introduction of sodium tetraiodophenolphthalein; $B$ and $C$ were taken 24 hours later. $C$ was taken after the removal of the gallbladder. Note the moth eaten appearance of the shadow cast by the gallbladder in $B$ and $C$, due to the precipitation of the salt. The periphery is well outlined in $(B)$.

difficult to understand how the concentration of iodine could vary considerably in different portions of the lumen of the gallbladder. Even though sodium tetraiodophenolphthalein were not freely diffusible in solution, physical mixing would tend to keep the solution within the gallbladder practically homogeneous.

In none of our roentgenograms was there any evidence of increased density in the center of the shadow. On the contrary, there was 
quite uniformly an increased density at the periphery of the shadow in the 18 hour roentgenograms (figs. 1 and 2).

Our data with sodium iodide are in agreement with the findings of Sweet. Sodium tetraiodophenolphthalein, however, was found to leave the gallbladder much more slowly so that we constantly recovered more from the gallbladder at the conclusion of an experiment than we did from the bag draining the right lower lobe except when the cystic duct was patent and a fat meal was given the animal.

I wish to thank Dr. I. S. Ravdin for advice and for his interest in this problem and Dr. H. K. Pancoast and Dr. E. P. Pendergrass for the interpretation of the roentgenograms.

\section{SUMMARY}

1. Potassium iodide is rapidly absorbed from the gallbladder.

2. Sodium tetraiodophenolphthalein is absorbed more slowly than potassium iodide.

3. The rate of absorption of sodium tetraiodophenolphthalein is so slow that it does not seem possible for absorption to explain the rapid changes occurring in clinical cholecystography.

4. We have not obtained any evidence which suggests that a fat meal increases the rate of absorption of the dye.

\section{BIBLIOGRAPHY}

1. Blond, K., Deutsche Med. Wchnschr., 1928, liv, 778. Zum Entleerungsmechansimus der extrahepatischen Gallenwege.

2. Sweet, J. E., Ann. Surg., 1929, xc, 939. The Function of the Gallbladder.

3. Demel, R., and Brummelkamp, R., Mitt. a. d. Grenzgeb. d. Med. u. Chir., 1924, xxxvii, 515. Ein Beitrag zur Funktion der Gallenblase.

4. Halpert, B., Med. Klinik., 1924, xx, 408. Neue Wege in der Gallenblasenforschung.

5. Treadwell and Hall, Analytic Chemistry. New York, 1924, 6th ed., Vol. ii, p. 559.

6. Kendall, E. C., J. Biol. Chem., 1920, xliii, 149. Determination of Iodine in Connection with Studies in Thyroid Activity.

7. Halpert, B. and Hanke, M. T., Am. J. Physiol., 1929, lxxxviii, 351. Observa tions on the Function of the Gallbladder. Experiments with Methylene Blue on Rabbits.

8. Rewbridge, A. G., Hanke, M. T., and Halpert, B., Am. J. Physiol., 1930, xcv, 511. Further Observations on the Function of the Gallbladder, Experiments with Methylene Blue on the Dog. 